DOI 10.1007/s10958-019-04482-9

Journal of Mathematical Sciences, Vol. 242, No. 3, October, 2019

\title{
In Memory of Professor Bogdan Bojarski
}

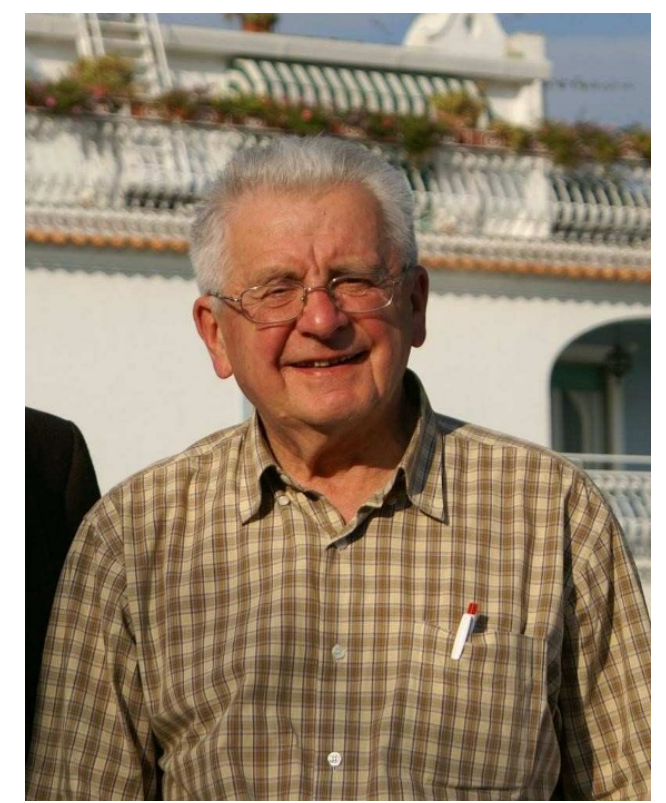

June 13, 1931 - December 22, 2018

Editorial Board of the Ukrainian Mathematical Bulletin was deeply saddened to learn of the passing away on December 22, 2018 of Bogdan Tadeusz Bojarski, one of the greatest mathematicians of his generation, a brilliant scientist and remarkable personality, a permanent member of the International Editorial Board of our journal. We appreciate the personal contribution of Professor Bojarski to the formation and development of our journal. Our thoughts are with his family, friends, colleagues, and all those whose professional paths crossed that of this eminent scientist.

Editorial Board of the Ukrainian Mathematical Bulletin 